\title{
Racism in Singapore: A Review and Recommendations for Future Research
}

\author{
Peter K.H. Chew \\ James Cook University, Singapore
}

\begin{abstract}
$R$ acism refers to 'the differential treatment enacted by an individual, group, or organization on individuals based on assumptions of a group's phenotypic, linguistic, or cultural differences' (Gamst, Liang, \& Der-Karabetian, 2011, p. 251). Currently, there is a lack of psychological research investigating racism in Singapore. The available research, narrative reviews, qualitative studies, and quantitative studies have yielded limited and inconclusive results. These researches are critically evaluated to provide four recommendations for a psychological research agenda: (a) develop a reliable and valid instrument to assess racism, (b) conduct experimental research to examine racism perpetuated by the majority or institutions, (c) examine the negative effects of racism, and (d) develop and evaluate interventions for racism.
\end{abstract}

Keywords: prejudice, discrimination, racism, racial relations, Singapore

There is a lack of psychological research investigating racism in Singapore. This lack is intriguing, given psychology's long-standing interest in the topic since Gordon Allport's (1954) seminal book, The Nature of Prejudice. Instead, racism in Singapore has been examined by researchers from diverse fields such as history (e.g., Barr, 2006), education (e.g., Khoo \& Lim, 2004), sociology (e.g., Velayutham, 2017), and even language and literature (e.g., Teo, 2005). However, researchers in these fields tend to use narrative reviews and qualitative methods. An objective investigation of racism is challenging, if not impossible, without the use of psychometric instruments and experimental methods, tools that are often used in psychology. This article aims to (a) briefly review psychological research on racism, (b) consider problems associated with the reluctance of Singaporeans to discuss racial issues and their endorsement of meritocracy, (c) critically evaluate the limited and inconclusive research on racism in Singapore, and (d) provide recommendations for a psychological research agenda.

\section{Psychological Research on Racism}

Racism refers to 'the differential treatment enacted by an individual, group, or organization on individuals based on assumptions of a group's phenotypic, linguistic, or cultural differences' (Gamst et al., 2011, p. 251). Due to the Civil Rights Movement in the 1960s, researchers argued that covert forms of racism have replaced overt racism in the United States. Covert forms of racism include ambivalent racism (Katz, 1981), aversive racism (Gaertner \& Dovidio, 1986), modern racism (McConahay, 1986), and symbolic racism (McConahay \& Hough, 1976). A similar phenomenon has been observed in other countries such as France, Germany, Britain, and the Netherlands (Pettigrew \& Meertens, 1995). Differences notwithstanding, these forms of racism share a common theme: individuals are more likely to identify themselves as non-racists while expressing prejudice or discriminating against others in subtle, socially justifiable ways. However, a literature review argued that overt and covert racism have always been expressed concurrently throughout history and that a distinction between the two is redundant (Leach, 2005). Indeed, at least one study in Australia found that overt racism is still prevalent and should not be discounted (Mellor, 2003). Nonetheless, as this article will illustrate, a distinction is useful because it informs the development of instruments and targeted interventions.

The negative effects of racism have been well documented. For example, the relationships between selfreported perceived racism and a range of negative physical and mental health outcomes have been documented in several literature reviews (Brondolo, Gallo, \& Myers, 2009; Paradies, 2006; Williams \& Mohammed, 2009) and at least two meta-analyses (Paradies et al., 2015; Pieterse, Todd, Neville, \& Carter, 2012). Racism has also been linked to reduced employment opportunities. Field experiments have been conducted where fictitious resumes, containing either a White name or a Black name, were sent in

Address for correspondence: Peter K.H. Chew, James Cook University, 149 Sims Drive, Singapore 387380. Email: peter.chew@jcu.edu.au 
response to job advertisements (Bertrand \& Mullainathan, 2004; Pager, Western, \& Bonikowski, 2009). The results indicated that resumes with a Black name are less likely to receive a call for an interview from employers. Overall, a review of field experiments concluded that a Black job seeker is ' 50 to 500 percent less likely to be considered by employers as an equally qualified White job applicant' (Pager, 2007, p. 114). Given these negative effects, interventions have been developed to reduce racism.

A large number of researches have been conducted on prejudice reduction (see Paluck \& Green, 2009, for a comprehensive review). Among these, two theories have received considerable empirical support. Contact theory states that prejudice will be reduced if intergroup contact takes place under four conditions: (a) equal status of groups, (b) common goals, (c) intergroup cooperation, and (d) support of authorities (Allport, 1954). A meta-analysis of 515 studies found a negative relationship between intergroup contact and prejudice (mean $r=-.22)$ and indicated that the four conditions are optimal, but not necessary, in the reduction of prejudice (Pettigrew \& Tropp, 2006; Pettigrew, Tropp, Wagner, \& Christ, 2011). Social identity theory states that we categorise people into groups, and this process results in the formation of in-groups (us) and out-groups (them) (Tajfel \& Turner, 1986). Because we derive our social identity and self-esteem via group membership, there is a tendency for in-group favouritism and outgroup derogation. Accordingly, an elimination or reorganisation of group boundaries should reduce prejudice (Bettencourt, Brewer, Croak, \& Miller, 1992; Crisp \& Hewstone, 1999, 2007; Gaertner \& Dovidio, 2005). For example, the Common Ingroup Identity Model (CIIM) proposed that the adoption of a superordinate identity (e.g., university students), in addition to a pre-existing identity (e.g., Whites or Blacks), reduces prejudices by encouraging individuals to view themselves as a single group (Gaertner \& Dovidio, 2005). This model has been supported by a series of experimental studies (reviewed in Gaertner \& Dovidio, 2005).

Although a large number of studies have provided insights into the nature of, effects of, and interventions for racism, the majority of the research has been conducted among American samples in the United States. It is erroneous to assume that these researches are generalisable since replication attempts of psychological research across cultures have achieved only moderate success (Smith, Fischer, Vignoles, \& Bond, 2013). For example, the concept of perfectionism (e.g., nature, consequences), developed using European American samples, has been shown to be different for a Taiwanese sample (Trotter, 2011), an African-American sample (Herman, Trotter, Reinke, \& Ialongo, 2011), and a Hong Kong sample (Suh, Yuen, Wang, $\mathrm{Fu}, \&$ Trotter, 2014). Accordingly, there is an urgent need to examine the generalisability of racism research to other cultures.

\section{Racial Relations in Singapore}

Singapore is a multiracial society consisting of four races: $74.1 \%$ of the population are Chinese, $13.4 \%$ Malays, 9.2\% Indians, and 3.3\% Others (Singapore Department of Statistics, 2010). Given the racial riots in the 1900s, the government implemented three initiatives to promote social integration: (a) public housing, (b) education, and (c) national service (Judd, 2005). Currently, over $80 \%$ of Singapore's population live in public housing (Housing \& Development Board, 2015), and racial quotas are enforced to prevent the formation of racial enclaves (Sim, Yu, \& Han, 2003). In 1997, the National Education program was launched in all public schools and universities to foster a common Singaporean identity and to educate students on Singapore's tumultuous past due to racial riots (Ministry of Education, Singapore, 1997). Lastly, under the National Service Act, all Singaporean males are conscripted for two years to serve in either the military (for the majority), police, or civil defence service, where they gain the opportunity to interact with males of all races (Judd, 2005).

Theoretically, the three government initiatives are consistent with intervention research on racism (Gaertner \& Dovidio, 2005; Pettigrew \& Tropp, 2006; Pettigrew et al., 2011). For example, the racial quotas on public housing and the participation in national service promotes intergroup contact, facilitating the reduction of prejudice (Pettigrew \& Tropp, 2006; Pettigrew et al., 2011). Also, the National Education program facilitates the adoption of a superordinate identity (i.e., Singaporeans) in addition to a pre-existing racial identity (e.g., Chinese or Malays). According to the CIIM, this identification with a single group should reduce prejudice (Gaertner \& Dovidio, 2005). Indeed, these initiatives appear to be successful; there have been no racial riots since the 1969 race riots of Singapore. However, it is unclear if the absence of racial riots is due to an effective reduction of prejudice or to the penalties imposed by the laws of Singapore.

Singapore has two laws that prohibit racism: The Sedition Act of Singapore (The Statutes of the Republic of Singapore, 1948) and Penal Code Chapter 224 (The Statutes of the Republic of Singapore, 1871). The Sedition Act makes it an offence for anyone to 'to promote feelings of ill-will and hostility between different races or classes of the population of Singapore' (The Statutes of the Republic of Singapore, 1948, p. 2). The Penal Code provides more details on the issue. Specifically, the code makes it an offence for anyone to intentionally wound ' . . . the religious or racial feelings of any person, utters any word or makes any sound in the hearing of that person, or makes any gesture in the sight of that person, or places any object in the sight of that person, or causes any matter however represented to be seen or heard by that person' (The Statutes of the Republic of Singapore, 1871, p. 135). Offenders will either be fined, imprisoned for up to three years, or both. These are not archaic laws that are no longer enforced; the Sedition Act has been used to arrest individuals for racist 
comments in recent years (e.g., AsiaOne News, 2012; The New Paper, 2008). However, while the government initiatives and these laws appear useful in reducing overt displays of racism, they are unable to address the protracted racial disparities in education and economic status.

Since the 1980s, Malays have been underperforming on educational achievement and economic indicators compared to Chinese and Indians (Mutalib, 2011). These racial disparities have not been resolved. According to the latest Population Census, only $5.1 \%$ of Malays obtained a university qualification compared to $22.6 \%$ of Chinese and 35\% of Indians (Singapore Department of Statistics, 2010). In addition, the median monthly household income for Malays was $\$ 3,844$ compared to $\$ 5,100$ for Chinese and $\$ 5,370$ for Indians. Lastly, only $2.8 \%$ of Malays live in private housing (i.e., condominiums and landed properties) compared to $18 \%$ of Chinese and $16.3 \%$ of Indians. Unfortunately, due to the reluctance of Singaporeans to discuss racial issues, it is unlikely that these disparities will be resolved in the near future.

\section{Reluctance to Discuss Racial Issues}

In general, Singaporeans seem motivated to maintain the belief that Singapore is an egalitarian and a meritocratic society. A recent survey of 2,000 Singaporeans provided some evidence for this proposition (Mathews, 2016). For example, about half ( $53 \%)$ believe that racism is no longer an important problem currently. This finding could be interpreted as an indicator of covert racism (i.e., modern racism; McConahay, Hardee, \& Batts, 1981). However, this belief might be justified in the absence of experimental evidence of racism in Singapore. The survey also suggested that Singaporeans are reluctant to discuss racial issues. For example, about two thirds (64\% to 66\%) think that discussions about racial issues cause unnecessary tension. More important, about half to two thirds ( $46 \%$ to $70 \%$ ) were not supportive of race-based information (about crime, educational performance, social problems, and so on) that could potentially reveal racial disparities.

The reluctance to discuss racial issues is problematic since the identification of racial disparities is the first step towards resolution. For example, the Council of Australian Governments identified disparities between nonIndigenous and Indigenous Australians and developed a comprehensive report to resolve those disparities (Council of Australian Governments, 2007). The report contains six specific measurable goals and a list of actions to be taken in order to achieve those goals. While there have been similar efforts in Singapore (e.g., tuition subsidies to close the income gap; Lian, 2013), the effectiveness of those efforts are unclear. Also, in the absence of a comprehensive plan with specific goals, it seems likely that the racial disparities that have existed since the 1980s will continue, or even worsen, in the next Population Census in 2020 (Mutalib, 2011). The situation is exacerbated by Singaporeans' endorsement of meritocracy, providing them with a plausible, albeit flawed, explanation for racial disparities.

\section{Endorsement of Meritocracy}

In the same survey, a majority of Singaporeans endorsed meritocracy (Mathews, 2016). Specifically, 73\% think that race is not an important determinant of success and $89 \%$ think that everyone, regardless of race, has an equal chance to be rich as long as they are hardworking. These findings are surprising given the problems associated with meritocracy (see Barr \& Low, 2005; Koh, 2014; Moore, 2000; Tan, 2008, for a comprehensive critique of meritocracy in Singapore). In particular, meritocracy assumes that everyone competes (or starts) with an equal background (e.g., regardless of race, socioeconomic status). Such an assumption ignores the potential benefits provided by race and wealth (Moore, 2000). For example, trainee teachers in Singapore tended to ascribe positive stereotypes to Chinese students (e.g., industrious) and negative stereotypes to Malay students (e.g., lazy; Khoo \& Lim, 2004). While the effect of such stereotypes on academic achievement in Singapore is currently unknown, four meta-analyses in the United States suggested that teachers' expectations vary depending on the race of the student (Tenenbaum \& Ruck, 2007) and that these expectations have a negative effect on racial minorities' academic achievement (McKown \& Weinstein, 2008; Rubie-Davies, Hattie, \& Hamilton, 2006).

Further, Chinese households earned an average of $\$ 1,256$ more per month than Malay households (Singapore Department of Statistics, 2010). The higher income allows Chinese to afford high-quality private tuition for their children and to send them to prestigious overseas universities (Moore, 2000). In turn, such opportunities allow Chinese children to obtain higher grades in schools and degrees in high-paying fields (e.g., medicine, law). This argument is partially supported by research conducted in the United States. A meta-analysis involving 101,157 students from 6,871 schools found a moderate to strong positive relationship between socioeconomic status (SES) and academic achievement (Sirin, 2005). In other words, children from high SES families tend to have higher academic achievement. Taken together, it seems that Chinese have an unfair advantage over the other races due to their race and wealth.

More important, the endorsement of meritocracy encourages Singaporeans to explain racial disparities using racial stereotypes. As mentioned, a majority of Singaporeans endorsed meritocracy, and about half of them believed that racism is no longer an important problem (Mathews, 2016). The combination of these attitudes encourages Singaporeans to attribute the cause of any educational or income disparities to the characteristics of the racial group (e.g., Malays have lower household income because they are lazy), effectively reinforcing negative stereotypes of the group. Indeed, research has found positive relationships 
between beliefs in meritocracy and racism (Bobocel, Son Hing, Davey, Stanley, \& Zanna, 1998; Poteat \& Spanierman, 2012). Unfortunately, the limited and inconclusive research on racism in Singapore precluded the consideration of racism as an alternative explanation for racial disparities.

\section{Racism Research in Singapore}

A comprehensive search was conducted on Google Scholar to identify published studies on racism in Singapore (up till March 2017). Key search terms included 'prejudice', 'discrimination', 'racism', 'racial relations', and 'Singapore'. Subsequently, reference lists of relevant publications were scrutinised for other relevant studies that were not found in the database. A total of 13 studies were found and cited in this section. Among these studies, seven (53.85\%) are narrative reviews, two $(15.38 \%)$ are qualitative studies, and four $(30.77 \%)$ are quantitative studies.

\section{Narrative Reviews}

The limited research on racism in Singapore has been dominated by narrative reviews (Barr, 2006; Barr \& Low, 2005; Chua, 2003; Moore, 2000; Mutalib, 2011; Teo, 2005; Walsh, 2007). These reviews tended to adopt a historical narrative, tracking policies from the 1960s to explain how Malays might be marginalised by the Singapore government (i.e., institutional racism). Some of these policies include the Speak Mandarin Campaign for the Chinese but there is an absence of similar campaigns for the respective languages of the other races (Teo, 2005). Also, primary school English textbooks in the 1980s tended to depict Malays in menial jobs (e.g., a street-sweeper) but Chinese in skilled jobs (e.g., a doctor; Barr, 2006). Furthermore, it is an open secret that Malays are excluded from serving in sensitive vocations in the military (Walsh, 2007). Lastly, the recurring pattern of Malays requesting equal treatment and the government's resistance to such requests has been documented (Mutalib, 2011). These reviews provided a compelling account of institutional racism and a strong rationale to study racism in Singapore.

There are two limitations associated with those reviews. First, there is little empirical evidence for some of their assertions. For example, anecdotal evidence aside, there is no empirical evidence to support the assertion that Malays are discriminated against in the military. In fact, the defence minister recently declared that the military does not discriminate against any individuals (Chow, 2015). Researchers need to show that the proportion of Malays in some military vocations are significantly lower than the expected proportion in the population in order to provide support for their assertion. Second, although this was not an aim of those reviews, it is difficult to demonstrate a causal link between racism in the past and racism in the present. For example, while the education system might have been racialised in the 1980s (Barr, 2006), its effects on Singaporeans' stereotypes of Malays in the present are unknown. The absence of a causal link enables Singaporeans to dismiss those findings as history: important but not necessarily relevant in today's society. Researchers need to provide current evidence of racism to persuade Singaporeans that racism is a contemporary issue.

\section{Qualitative Studies}

There are at least two qualitative studies that have examined perceived racism in everyday situations toward Indians (Velayutham, 2006) and Malays (Velayutham, 2016). The methodology of the first study was not stated; it seems that semi-structured interviews were conducted with Indians in their early twenties to their thirties. Although Indians seem to be doing better than Chinese on educational achievement and economic indicators (Singapore Department of Statistics, 2010), the study reported that Indians experienced racism in the form of 'name-calling' associated with their body (e.g., smelly) and skin colour (e.g., dark) in various situations like schools, public transport, and swimming pools (Velayutham, 2006). In the second study, semi-structured interviews were conducted with Malays about their working experience in Singapore. The study highlighted the privileges enjoyed by Chinese: they are more likely to obtain preferential treatment from their superiors (usually Chinese), salary increases, and promotion than the other races (Velayutham, 2017). The results were supplemented by high-profile cases of racism in social media. These studies provided an in-depth understanding of minorities' experience of racism in Singapore.

There are a few limitations associated with qualitative studies (Anderson, 2010). For example, findings from qualitative studies are vulnerable to researcher bias due to the nature of data collection (e.g., semi-structured interviews) and cannot be generalised to the population at large because of the small sample sizes. Also, the small sample sizes make it likely that the findings will be dismissed as an exception to the norm in egalitarian and meritocratic Singapore. Indeed, in one high-profile case of racism, the prime minister rebuked the offender but asserted that it was 'an isolated case that does not reflect the strength of race relations in Singapore' (Ho, 2012, para. 6; Velayutham, 2016). Despite the strengths associated with qualitative studies (Anderson, 2010), it appears that quantitative experimental research are needed to provide conclusive evidence of racism in Singapore. Unfortunately, most of the quantitative studies are descriptive in nature.

\section{Quantitative Studies}

Currently, only a few studies have examined racism quantitatively. Of these, one is a journal article (Ooi, 2005) and the rest are institutional reports (i.e., not likely to be peerreviewed; Chin \& Vasu, 2012; Mathews, 2013, 2016). In general, the conclusions from these studies are inconsistent with those from the narrative reviews and qualitative studies. For example, a descriptive survey found that racial relations in Singapore have improved from 1990 to 2001; 
there was an increase in the percentage of Chinese who reported inviting friends of other races to celebrate special occasions (Ooi, 2005). Also, across all races, $80 \%$ of the participants indicated support for having multiple races in Singapore. Another study conducted face-to-face interviews using a set of survey questions (e.g., 'Would you mind if your next-door neighbour were a Malay?') and found evidence for strong multiracial ties in Singapore (Chin \& Vasu, 2012). The last two studies administered questionnaires using a set of survey questions (e.g., 'People from all races should be treated equally') in the homes of Singaporeans, to examine racial harmony (Mathews, 2013, 2016). Overall, although there is some evidence of racism, the results from both studies provided support for racial harmony in Singapore. Taken together, these studies suggested that racism might not be an issue in Singapore.

The predominantly descriptive nature of the studies is a limitation. For example, most of the questionnaires have not been subjected to psychometric investigations. Consequently, it is debatable whether those studies were assessing multicultural resilience (Chin \& Vasu, 2012), racial harmony (Mathews, 2013), and race relations (Mathews, 2016). Also, asking participants to accurately report on their own attitudes and experiences is difficult for four reasons. First, participants might respond in a manner that presents a positive image of themselves (i.e., the social desirability bias; Paulhus, 1991). For example, $96 \%$ of the participants indicated agreement with the item 'People from all races should be treated equally' (Mathews, 2016). In this instance, they might have provided a socially desirable response in order to appear non-racist. Second, participants might not provide truthful responses due to the lack of anonymity, as their home address is identified (Chin \& Vasu, 2012; Mathews, 2013, 2016). The fear of being arrested under the Sedition Act could have inhibited the expression of racism.

Third, consistent with how racism has evolved in other developed countries (e.g., Pettigrew \& Meertens, 1995), racism in contemporary Singapore is likely to be covert, instead of overt, in nature. For example, participants might identify as a non-racist but discriminate in subtle, socially justifiable manners (Dovidio \& Gaertner, 2000). However, most of the studies appeared to be assessing overt racism only (Chin \& Vasu, 2012; Mathews, 2013, 2016). Lastly, variables that could not be controlled for in descriptive studies might have affected the accuracy of participants' responses. For example, one study found that only $33 \%$ of Malays and 36\% of Indians reported that they experienced racism (Mathews, 2016). Such a finding is probably an underestimation since minorities with meritocratic beliefs tended to under-report instances of racism (Major et al., 2002). Also, minorities might be unable to detect subtle covert racism, resulting in lower levels of perceived racism (Barreto \& Ellemers, 2015). Taken together, it would be premature to conclude that racism might not be an issue in Singapore.
In summary, the limited research on racism has yielded inconsistent results. Also, the limitations associated with these studies precluded an accurate evaluation of racial relations in Singapore. In turn, the absence of such an evaluation prevented an identification of the actual causes of racial disparities. Given the importance of resolving racial disparities, this article makes four sequential recommendations for future research on racism in Singapore.

\section{Recommendations for a Psychological Research Agenda}

First, a reliable and valid instrument should be developed to assess both overt and covert racism in Singapore. Existing instruments are inappropriate because they were developed for minorities in other countries and might not be applicable to the Singaporean context. For example, the item 'Generally speaking, I favour full racial integration' on the Modern Racism Scale (McConahay et al., 1981) is not applicable because there has never been racial segregation in Singapore. The instrument developed to assess racism in Singapore should be administered online with a measure of social desirability (Paulhus, 1991) to preserve anonymity and to control for the social desirability bias. This procedure allows researchers to examine the prevalence of racism in the population. More important, the availability of such an instrument enables researchers to evaluate the effectiveness of interventions designed to reduce racism.

Second, experimental research should be conducted to examine racism perpetuated by the majority or institutions. For example, field experiments could be conducted by sending resumes containing either a Chinese name or a Malay name in response to job advertisements in Singapore (Bertrand \& Mullainathan, 2004; Pager et al., 2009). Evidence of racism would be obtained if Malay candidates received significantly fewer calls for interviews than equally qualified Chinese candidates. The results would provide an alternative explanation for racial disparities. Specifically, the observed lower monthly household income for Malays (Singapore Department of Statistics, 2010) could be due to discrimination during the hiring process, resulting in reduced employment opportunities for them. In addition, experimental researches tend to have large sample sizes (cf. qualitative studies), preventing the findings from being dismissed as an exception to the norm.

Third, the negative effects of racism on important variables should be examined. For example, positive relationships have been found between perceived racism and a range of negative physical and mental health outcomes (Brondolo et al., 2009; Paradies, 2006; Paradies et al., 2015; Pieterse et al., 2012; Williams \& Mohammed, 2009). Hence, researchers could examine whether there are racial disparities in health outcomes and determine the extent to which racism is a contributor to those disparities. Also, given that Singapore uses the education system as a 
meritocratic identification system for talents (Moore, 2000), it is important that researchers examine the effects of racism on educational achievement of minorities. For example, since teachers hold negative stereotypes of Malay students (Khoo \& Lim, 2004), researchers could examine its effects on the educational achievement of Malays. Evidence of a negative effect would cast doubts on the egalitarian nature of the education system. Given the positive relationships between beliefs in meritocracy and racism (Bobocel et al., 1998; Poteat \& Spanierman, 2012), an awareness of the problems associated with meritocracy could serve as a potential intervention for racism.

Fourth, interventions for racism should be developed and evaluated. Specifically, researchers could evaluate the generalisability of known interventions to the Singaporean context. For example, researchers could examine whether intergroup contact would lead to a reduction of prejudice (Pettigrew \& Tropp, 2006; Pettigrew et al., 2011). Also, researchers could use the CIIM (Gaertner \& Dovidio, 2005 ) and examine whether the adoption of a superordinate identity (e.g., Singaporeans) would reduce prejudice. While laws like the Sedition Act (The Statutes of the Republic of Singapore, 1948) might be useful in discouraging overt racism, such interventions have the potential to reduce both overt and covert racism.

In conclusion, this article makes four recommendations for a psychological research agenda in Singapore. These recommendations should improve the quality and quantity of racism research. In particular, the use of experimental research provides strong evidence of racism whereas an examination of the negative effects of racism could highlight problems associated with meritocracy. In turn, the empirical evidence could address Singaporeans' reluctance to discuss racial issues and their endorsement of meritocracy. With these barriers removed, the interventions for racism have the potential to finally resolve the protracted racial disparities between Malays and the other races in Singapore.

\section{References}

Allport, G.W. (1954). The nature of prejudice. Reading, MA: Addison-Wesley.

Anderson, C. (2010). Presenting and evaluating qualitative research. American Journal of Pharmaceutical Education, 74, $1-7$.

AsiaOne News. (2012, July 1). 2 arrested for making racist remarks online. Retrieved from http://news.asiaone.com/ News/AsiaOne+News/Crime/Story/A1Story20120701356542.html

Barr, M.D. (2006). Racialised education in Singapore. Educational Research for Policy and Practice, 5, 15-31.

Barr, M.D., \& Low, J. (2005). Assimilation as multiracialism: The case of Singapore's Malays. Asian Ethnicity, 6, 161-182. https://doi.org/10.1080/14631360500226606

Barreto, M., \& Ellemers, N. (2015). Chapter three - Detecting and experiencing prejudice: New answers to old ques- tions. Advances in Experimental Social Psychology, 52, 139219. https://doi.org/10.1016/bs.aesp.2015.02.001

Bertrand, M., \& Mullainathan, S. (2004). Are Emily and Greg more employable than Lakisha and Jamal? A field experiment on labor market discrimination. American Economic Review, 94, 991-1013. https://doi.org/10.1257/0002828042002561

Bettencourt, B.A., Brewer, M.B., Croak, M.R., \& Miller, N. (1992). Cooperation and the reduction of intergroup bias: The role of reward structure and social orientation. Journal of Experimental Social Psychology, 28, 301-319.

Bobocel, D.R., Son Hing, L.S., Davey, L.M., Stanley, D.J., \& Zanna, M.P. (1998). Justice-based opposition to social policies: Is it genuine? Journal of Personality and Social Psychology, 75, 653-669. https://doi.org/10.1037/0022-3514.75.3.653

Brondolo, E., Gallo, L.C., \& Myers, H.F. (2009). Race, racism and health: Disparities, mechanisms, and interventions. Journal of Behavioral Medicine, 32, 1-8.

Chin, Y., \& Vasu, N. (2012). The ties that bind \& blind: A report on inter-racial and inter-religious relations in Singapore. Singapore: Centre of Excellence for National Security, S. Rajaratnam School of International Studies, Nanyang Technological University. Retrieved from https://www.rsis.edu.sg/wpcontent/uploads/2014/10/PB121231_The_Ties_that_ Bind__Blind.pdf

Chow, J. (2015, February 16). Malays deployed in the SAF as sailors: Ng Eng Hen. The Straits Times. Retrieved from http://www.straitstimes.com/singapore/malays-deployedin-the-saf-as-sailors-ng-eng-hen

Chua, B.H. (2003). Multiculturalism in Singapore: An instrument of social control. Race \& Class, 44, 58-77. https://doi.org/10.1177/0306396803044003025

Council of Australian Governments. (2007). National Indigenous Reform Agreement (Closing the Gap). Retrieved from http://www.federalfinancialrelations.gov.au/content/npa/ health/_archive/indigenous-reform/national-agreement_ sept_12.pdf

Crisp, R.J., \& Hewstone, M. (1999). Differential evaluation of crossed category groups: Patterns, processes, and reducing intergroup bias. Group Processes \& Intergroup Relations, 2, 307-333.

Crisp, R.J., \& Hewstone, M. (2007). Multiple social categorization. Advances in Experimental Social Psychology, 39, 163-254.

Dovidio, J.F., \& Gaertner, S.L. (2000). Aversive racism and selection decisions: 1989 and 1999. Psychological Science, 11, 315-319.

Gaertner, S.L., \& Dovidio, J.F. (1986). The aversive form of racism. In J.F. Dovidio \& S.L. Gaertner (Eds.), Prejudice, discrimination, and racism (pp. 61-89). Orlando, FL: Academic Press.

Gaertner, S.L., \& Dovidio, J.F. (2005). Understanding and addressing contemporary racism: From aversive racism to the common ingroup identity model. Journal of Social Issues, 61, 615-639. https://doi.org/10.1111/j.1540-4560.2005.00424.x

Gamst, G.C., Liang, C.T.H., \& Der-Karabetian, A. (2011). Handbook of multicultural measures. Los Angeles, CA: Sage. 
Herman, K.C., Trotter, R., Reinke, W.M., \& Ialongo, N. (2011). Developmental origins of perfectionism among African American youth. Journal of Counseling Psychology, 58, 321334. https://doi.org/10.1037/a0023108

Ho, D. (2012, October 8). PM Lee, ministers condemn racist remarks on Facebook. The Straits Times. Retrieved from http://www.straitstimes.com/singapore/pm-lee-ministerscondemn-racist-remarks-on-facebook

Housing \& Development Board. (2015). Public housing - A Singapore icon. Retrieved December 21, 2016, from http://www.hdb.gov.sg/cs/infoweb/about-us/our-role/ public-housing-a-singapore-icon

Judd, M. (2005). Is harmony possible in a multiracial society? The case of Singapore. In R. Pinxten \& E. Preckler (Eds.), Racism in metropolitan areas (pp. 107-111). New York, NY: Berghahn Books.

Katz, I. (1981). Stigma: A social psychological analysis. Hillsdale, NJ: Erlbaum.

Khoo, A., \& Lim, K.M. (2004). Trainee teachers' stereotypes of ethnic groups in Singapore. In A.E. Lai (Ed.), Beyond rituals and riots: Ethnic pluralism and social cohesion in Singapore (pp. 197-227). Singapore: Eastern Universities Press.

Koh, A. (2014). Doing class analysis in Singapore's elite education: Unravelling the smokescreen of 'meritocratic talk.' Globalisation, Societies and Education, 12, 196-210. https://doi.org/10.1080/14767724.2014.888308

Leach, C.W. (2005). Against the notion of a 'new racism'. Journal of Community \& Applied Social Psychology, 15, 432-445. https://doi.org/10.1002/casp.841

Lian, G.C. (2013, August 24). Two new steps to help MalayMuslim community shrink income gap, increase social mobility. The Straits Times. Retrieved from http://www. straitstimes.com/singapore/two-new-steps-to-help-malaymuslim-community-shrink-income-gap-increase-socialmobility

Major, B., Gramzow, R.H., McCoy, S.K., Levin, S., Schmader, T., \& Sidanius, J. (2002). Perceiving personal discrimination: The role of group status and legitimizing ideology. Journal of Personality and Social Psychology, 82, 269-282. https://doi.org/10.1037/0022-3514.82.3.269

Mathews, M. (2013). Indicators of racial and religious harmony. Singapore: Institute of Policy Studies, National University of Singapore.

Mathews, M. (2016). Channel NewsAsia-Institute of Policy Studies (CNA-IPS) survey on race relations. Singapore: Institute of Policy Studies, National University of Singapore.

McConahay, J.B. (1986). Modern racism, ambivalence, and the Modern Racism Scale. In J.F. Dovidio \& S.L. Gaertner (Eds.), Prejudice, Discrimination, and Racism (pp. 91-125). Orlando, FL: Academic Press.

McConahay, J.B., Hardee, B.B., \& Batts, V. (1981). Has racism declined in America? It depends on who is asking and what is asked. Journal of Conflict Resolution, 25, 563-579.

McConahay, J.B., \& Hough, J.C. (1976). Symbolic racism. Journal of Social Issues, 32, 23-45. https://doi.org/ 10.1111/j.1540-4560.1976.tb02493.x
McKown, C., \& Weinstein, R.S. (2008). Teacher expectations, classroom context, and the achievement gap. Journal of School Psychology, 46, 235-261. https://doi.org/ 10.1016/j.jsp.2007.05.001

Mellor, D. (2003). Contemporary racism in Australia: The experiences of Aborigines. Personality and Social Psychology Bulletin, 29, 474-486.

Ministry of Education, Singapore. (1997). National Education. Retrieved December 15, 2016, from https://www. moe.gov.sg/media/press/1997/pr01797.htm

Moore, R.Q. (2000). Multiracialism and meritocracy: Singapore's approach to race and inequality. Review of Social Economy, 58, 339-360. https://doi.org/10.1080/ 00346760050132364

Mutalib, H. (2011). The Singapore minority dilemma. Asian Survey, 51, 1156-1171. https://doi.org/ 10.1525/as.2011.51.6.1156

Ooi, G.L. (2005). The role of the developmental state and interethnic relations in Singapore. Asian Ethnicity, 6, 109-120. https://doi.org/10.1080/14631360500135336

Pager, D. (2007). The use of field experiments for studies of employment discrimination: Contributions, critiques, and directions for the future. The Annals of the American Academy of Political and Social Science, 609, 104-133.

Pager, D., Western, B., \& Bonikowski, B. (2009). Discrimination in a low-wage labor market a field experiment. American Sociological Review, 74, 777-799.

Paluck, E.L., \& Green, D.P. (2009). Prejudice reduction: What works? A review and assessment of research and practice. Annual Review of Psychology, 60, 339-367. https://doi.org/10.1146/annurev.psych.60.110707.163607

Paradies, Y. (2006). A systematic review of empirical research on self-reported racism and health. International Journal of Epidemiology, 35, 888-901. https://doi.org/10.1093/ije/dyl056

Paradies, Y., Ben, J., Denson, N., Elias, A., Priest, N., Pieterse, A., ... Gee, G. (2015). Racism as a determinant of health: A systematic review and meta-analysis. PLoS One, 10, e0138511. https://doi.org/10.1371/journal.pone.0138511

Paulhus, D.L. (1991). Measurement and control of response bias. In J.P. Robinson, P.R. Shaver, \& L.S. Wrightsman (Eds.), Measures of personality and social psychological attitudes (pp. 17-59). San Diego, CA: Academic Press.

Pettigrew, T.F., \& Meertens, R.W. (1995). Subtle and blatant prejudice in Western Europe. European Journal of Social Psychology, 25, 57-75.

Pettigrew, T.F., \& Tropp, L.R. (2006). A meta-analytic test of intergroup contact theory. Journal of Personality and Social Psychology, 90, 751-783.

Pettigrew, T.F., Tropp, L.R., Wagner, U., \& Christ, O. (2011). Recent advances in intergroup contact theory. International Journal of Intercultural Relations, 35(3), 271-280. https://doi.org/10.1016/j.ijintrel.2011.03.001

Pieterse, A.L., Todd, N.R., Neville, H.A., \& Carter, R.T. (2012). Perceived racism and mental health among Black American adults: A meta-analytic review. Journal of Counseling Psychology, 59, 1-9. https://doi.org/10.1037/a0026208 
Poteat, V.P., \& Spanierman, L.B. (2012). Modern racism attitudes among white students: The role of dominance and authoritarianism and the mediating effects of racial colorblindness. The Journal of Social Psychology, 152(6), 758-774. https://doi.org/10.1080/00224545.2012.700966

Rubie-Davies, C., Hattie, J., \& Hamilton, R. (2006). Expecting the best for students: Teacher expectations and academic outcomes. British Journal of Educational Psychology, 76, 429444. https://doi.org/10.1348/000709905X53589

Sim, L.L., Yu, S.M., \& Han, S.S. (2003). Public housing and ethnic integration in Singapore. Habitat International, 27, 293-307. https://doi.org/10.1016/S0197-3975(02)00050-4

Singapore Department of Statistics. (2010). Census of population 2010 Statistical release 2: Households and housing. Singapore: Author.

Sirin, S.R. (2005). Socioeconomic status and academic achievement: A meta-analytic review of research. Review of Educational Research, 75, 417-453.

Smith, P.B., Fischer, R., Vignoles, V.L., \& Bond, M.H. (2013). Understanding social psychology across cultures: Engaging with others in a changing world. Thousand Oaks, CA: Sage.

Suh, H.N., Yuen, M., Wang, K.T., Fu, C.-C., \& Trotter, R.H. (2014). Comparing perfectionist types on family environment and well-being among Hong Kong adolescents. Personality and Individual Differences, 70, 111-116. https://doi.org/10.1016/j.paid.2014.06.023

Tajfel, H., \& Turner, J.C. (1986). The social identity theory of intergroup behavior. In S. Austin \& W.G. Austin (Eds.), Psychology of intergroup relations (pp. 7-24). Chicago: NelsonHall.

Tan, K.P. (2008). Meritocracy and elitism in a global city: Ideological shifts in Singapore. International Political Science Review / Revue Internationale de Science Politique, 29, $7-27$.
Tenenbaum, H.R., \& Ruck, M.D. (2007). Are teachers' expectations different for racial minority than for European American students? A meta-analysis. Journal of Educational Psychology, 99, 253-273. https://doi.org/ 10.1037/0022-0663.99.2.253

Teo, P. (2005). Mandarinising Singapore: A critical analysis of slogans in Singapore's 'Speak Mandarin' campaign. Critical Discourse Studies, 2(2), 121-142. https://doi.org/ $10.1080 / 17405900500283565$

The New Paper. (2008, May 21). Blogger arrested for posting racist online content. Retrieved from http://news. asiaone.com/News/AsiaOne+News/Singapore/Story/ A1Story20080521-66273.html

The Statutes of the Republic of Singapore. Penal Code, 298 Chapter $224 \$(1871)$.

The Statutes of the Republic of Singapore. Sedition Act, Chapter $290 \$(1948)$.

Trotter, R. (2011). Perfectionism, coping, adjustment and achievement in Taiwanese culture ( Unpublished doctoral dissertation). University of Missouri-Columbia, United States.

Velayutham, S. (2006, September). Everyday racism in Singapore. Paper presented at the Everyday Multiculturalism Conference Proceedings, Sydney, Australia.

Velayutham, S. (2016). Races without racism?: Everyday race relations in Singapore. Identities, 24, 455-473. https://doi.org/10.1080/1070289X.2016.1200050

Walsh, S.P. (2007). The roar of the lion city ethnicity, gender, and culture in the Singapore armed forces. Armed Forces \& Society, 33, 265-285. https://doi.org/ 10.1177/0095327X06291854

Williams, D.R., \& Mohammed, S.A. (2009). Discrimination and racial disparities in health: Evidence and needed research. Journal of Behavioral Medicine, 32, 20-47. https:// doi.org/10.1007/s10865-008-9185-0 